Available online at GSC Online Press Directory

GSC Biological and Pharmaceutical Sciences

e-ISSN: 2581-3250, CODEN (USA): GBPSC2

Journal homepage: https://www.gsconlinepress.com/journals/gscbps

(RESEARCH ARTICLE)

\title{
Biochemical and histomorphological changes in liver and kidney of Rattus norvegicus domestica rats following tetracycline administration
}

\author{
Emmanuel Tonbra Egoro *, Ikhide Godwin Ilegbedion and Sonia Osaro Aibangbe \\ Department of Medical Laboratory Science, Faculty of Basic Medical Sciences, College of Health Sciences, Niger Delta \\ University, P.M.B. 071, Wilberforce Island, Bayelsa State, Nigeria.
}

Publication history: Received on 22 October 2019; revised on 28 August 2020; accepted on 30 August 2020

Article DOI: https://doi.org/10.30574/gscbps.2020.12.2.0200

\begin{abstract}
This study was aimed on assessing the biochemical and histomorphological changes in liver and kidney of Rattus norvegicus domestica rats following tetracycline administration. Five ml blood specimen was collected from twenty one rats weighing $0.2072-0.3062 \mathrm{~kg}$ into lithium heparin bottles with seven of them each administered with $0.12 \mathrm{mg} / 0.2072$ $\mathrm{kg}$ of tetracycline for two weeks (short term toxicity study) and four weeks (long term toxicity study) respectively, while the remaining seven which served as control group were not administered with tetracycline. The following biochemical parameters: alanine aminotransferase, aspartate aminotransferase, urea and creatinine were measured quantitatively. The mean values of all the measured biochemical parameters in the short term toxicity study were not statistically significant $(p \geq 0.05)$ as compared to the control group and these values were also in conformity to the histomorphological study of the liver and kidney organs while that of the long term toxicity study showed statistically significant differences $(\mathrm{p} \leq 0.05)$ in all the measured biochemical parameters as compared to the control group and also in conformity to the histomorphological study of the liver and kidney organs. In conclusion, administration of 0.12 $\mathrm{mg} / 0.2072 \mathrm{~kg}$ of tetracycline for four weeks may induce changes in the biochemical and histomorphological study of liver and kidney of Rattus norvegicus domestica rats, while that of two weeks may not. It is therefore recommended that tetracycline capsule should not be used indiscriminately for a long period. Besides, routine estimation of these biochemical parameters should be carried out in long term administration of tetracycline in humans.
\end{abstract}

Keywords: Biochemical changes; Histomorphological changes; Liver; Kidney; Rattus norvegicus domestica; Tetracycline administration

\section{Introduction}

Tetracycline is an odorless, yellow crystalline powder antibiotic used for the treatment of infections, such as: malaria, syphilis, brucellosis, cholera, acne etc as well as rheumatic and dermatological inflammatory conditions with some common side effects such as vomiting, itching, rash and discoloration of teeth in children that are lesser than eight years old etc. This antibiotic is also a bacteriostatic agent with a wide spectrum of antimicrobial activity having effects on bone development hence not advisable to be used by pregnant women or nursing mother [1].

The protein inhibiting properties of this antibiotic make it effective in preventions as well as treatment of several diseases that are infectious. This antibiotic plays a significant role in both veterinary and human medicine, but microbial resistance has limited its effectiveness. The active substance in this antibiotic is tetracycline hydrochloride with a chemical name known as 4-(Dimethylamino)1,4,4a,5,5a,6,11,12a-octahydro-3,6,10,12,-12apentahydroxy-6-methyl1,11-dioxo2-napthacenecar boxamindemonohydrochloride [2].

\footnotetext{
* Corresponding author: Emmanuel Tonbra Egoro

Department of Medical Laboratory Science, Faculty of Basic Medical Sciences, College of Health Sciences, Niger Delta University, P.M.B. 071, Wilberforce Island, Bayelsa State, Nigeria.
} 
This antibiotic which is readily absorbed is binded to plasma protein, concentrated by the liver in the bile and excreted via urine and faeces [3]. It is well absorbed from gastrointestinal tract via oral administration and adequately distributed in the body with the liver and kidney accounting for the highest levels [4]. The recommended oral daily dosage is $1000-2000 \mathrm{mg} /$ day (therapeutic dose). Oral doses of 250 to $500 \mathrm{mg}$ every 6 hours produce plasma concentrations within the range of 1 to $5 \mathrm{mg} / \mathrm{l}$ (therapeutic blood concentrations) [5].

Regardless of the side effects of tetracycline when used indiscriminately, this capsule is still widely abused by many individuals especially for the treatment of various diseases without the prescription of a physician. This study therefore aims to investigate changes in the plasma biochemical parameters such as alanine aminotransferase, aspartate aminotransferase, urea and creatinine as well as histomorphological study of the liver and kidney organs following the oral administration of this capsule for two weeks (short term toxicity study) and four weeks (long term toxicity study) respectively using Rattus norvegicus domestica rats as the experimental animals since such study is rarely available in the studied community.

\section{Material and methods}

\subsection{Tetracycline}

The 250 mg tetracycline capsule used for this research work was purchased in Cynflac Pharmacy in Yenagoa, Bayelsa State of Nigeria and manufactured by ZIM Laboratory Limited India. The capsule which is of analytical grade was stored following strictly the storage instruction as recommended by the manufacturer.

\subsection{Animals}

Twenty one (21) Rattus norvegicus domestica rats weighing between $0.2072-0.3062 \mathrm{~kg}$ were purchased from a reputable animal house in Yenagoa Bayelsa State, Nigeria and transported to the animal house of the Department of Medical Laboratory Science, Niger Delta University, Wilberforce Island, Bayelsa State, Nigeria via a public transport. The rats were kept in ventilated rat cages and were allowed to acclimatized for two weeks prior to the commencement of the research work and fed with growers mash hybrid feeds (pre-mix rat feed) and water (ad libitium).

\subsection{Ethical clearance}

Sample collection and procedures for this research work were carried out in conformity to the National Guidelines for animal usage in research as approved by the University Research Ethical Committee.

\subsection{Experimental study}

\subsection{Pilot study}

A pilot study was carried out in order to ascertain the minimum dose of tetracycline that can cause $50 \%$ death (LD50) in the experimental rats and this was obtained with $0.220 \mathrm{mg} / 0.2072 \mathrm{~kg}$ of tetracycline capsule dissolved in $8 \mathrm{ml}$ of distilled water.

\subsection{Short and long term toxicity studies}

In these studies seven experimental rats weighing between 0.2072-0.3062 kg were administered orally via gastric intubation with $0.12 \mathrm{mg} / 0.2072 \mathrm{~kg}$ of tetracycline capsule dissolved in $8 \mathrm{ml}$ of distilled water daily for a period of two weeks (short term toxicity study) while another seven experimental rats weighing between $0.2072-0.3062 \mathrm{~kg}$ were administered orally via gastric intubation with $0.12 \mathrm{mg} / 0.2072 \mathrm{~kg}$ of tetracycline capsule dissolved in $8 \mathrm{ml}$ of distilled water daily for a period of four weeks (long term toxicity study). The remaining seven rats weighing between $0.2072-$ $0.3062 \mathrm{~kg}$ which served as control group were not administered with tetracycline or any other $\operatorname{drug}(\mathrm{s})$.

Twenty-four hours after the last treatment with $0.12 \mathrm{mg} / 0.2072 \mathrm{~kg}$ of tetracycline in both the short and long term toxicity study groups respectively the rats were then anaesthetized in a chloroform-saturated chamber alongside the rats in the control group, thereafter five ml of blood specimen was collected from each of them by cardiac puncture. The blood specimens were introduced into lithium heparin anti-coagulated bottles, mixed carefully to ensure homogeneity and prevention of blood clot after which each blood specimen was spun at 2500 revolution per minute (rpm) for 10 minutes using a Gulfex Medfield Equipment and Scientific Limited Macro-centrifuge with model number 800D. The obtained plasma was then used for the measurement of the following biochemical parameters: alanine aminotransferase, colorimetric method as described by Schmidt and Schmidt in the manual of Randox Laboratories Limited, 55, Diamond Road, Crumlin, County Antrim, BT294QY, United Kingdom and modified by [6], aspartate 
aminotransferase, colorimetric method as described by Schmidt and Schmidt in the manual of Randox Laboratories Limited, 55, Diamond Road, Crumlin, County Antrim, BT294QY, United Kingdom and modified by [6] urea, urease Berthelot's method as described by Weatherburn in 1967 in the manual of Randox Laboratories Limited, 55, Diamond Road, Crumlin, County Antrim, BT294QY, United Kingdom and modified by [7] and creatinine, Jaffe reaction method as described by Henry in 1974 in the manual of Randox Laboratories Limited, Ardmore Diamond Road, Crumlin, Co. Antrim, United Kingdom, BT294QY and modified by [7] using a Vis-Spectrophotometer with model number S23A.

After this the Rattus norvegicus domestica rats were sacrificed with the liver and kidney removed from the control and experimental groups (short and long term toxicity study) respectively by cervical dislocation, fixed in $10 \%$ formal saline and processed for histomorphological study using the method according to [8]. The processed tissues were sectioned at $5 \mu \mathrm{m}$ using the rotary microtome (Leica RM 2125) and further floated in water bath, attached to slides and stained using haematoxylin and eosin dyes with photomicrography taken using a binocular light compound microscope at x100 magnification.

\subsection{Statistical analysis}

The results of this study were expressed as mean and standard deviation, while the differences between the subjects (control and experimental groups) were assessed using the student' ' $t$ ' test. The results were considered statistically significant at $\mathrm{p} \leq 0.05$.

\section{Results and discussion}

The results of the biochemical parameters measured in the Rattus norvegicus domestica rats (control group) and Rattus norvegicus domestica rats (experimental group) administered with $0.12 \mathrm{mg} / 0.2072 \mathrm{~kg}$ tetracycline for 2 weeks (short term toxicity study) are shown in Table 1 while that of the control group and experimental group administered with $0.12 \mathrm{mg} / 0.2072 \mathrm{~kg}$ of tetracycline for four weeks (long term toxicity study) are shown in Table 2

Table 1 Biochemical parameters in plasma of Rattus norvegicus domestica rats following the administration of 0.12 $\mathrm{mg} / 0.2072 \mathrm{~kg}$ tetracycline for 2 weeks (short term toxicity study) compared with the control rats.

\begin{tabular}{|l|l|l|l|l|}
\hline Parameters & $\begin{array}{l}\text { Control group } \\
(\mathbf{n = 7})\end{array}$ & $\begin{array}{l}\text { Experimental group } \\
(\mathbf{n = 7})\end{array}$ & P-value & Remark \\
\hline ALT (U/L) & $4.40 \pm 0.28$ & $4.43 \pm 0.29$ & $\mathrm{P} \geq 0.05$ & NS \\
\hline AST (U/L) & $3.70 \pm 0.20$ & $3.72 \pm 0.21$ & $\mathrm{P} \geq 0.05$ & NS \\
\hline Urea $(\mathrm{mmol} / \mathrm{L})$ & $3.33 \pm 1.02$ & $3.32 \pm 1.04$ & $\mathrm{P} \geq 0.05$ & $\mathrm{NS}$ \\
\hline Creatinine $(\mu \mathrm{mol} / \mathrm{L})$ & $66.52 \pm 3.30$ & $66.54 \pm 3.32$ & $\mathrm{P} \geq 0.05$ & $\mathrm{NS}$ \\
\hline
\end{tabular}

KEYS: Values are in means \pm Standard Deviation (SD); ALT = Alanine aminotransferase; AST = Aspartate aminotransferase; NS = Not statistically significant; $\mathrm{n}=$ number of rats

Table 2 Biochemical parameters in plasma of Rattus norvegicus domestica rats following the administration of 0.12 $\mathrm{mg} / 0.2072 \mathrm{~kg}$ of tetracycline for 4 weeks (long term toxicity study) compared with the control rats.

\begin{tabular}{|l|l|l|l|l|}
\hline Parameters & $\begin{array}{l}\text { Control group } \\
(\mathbf{n = 7})\end{array}$ & $\begin{array}{l}\text { Experimental group } \\
(\mathbf{n = 7})\end{array}$ & P-value & Remark \\
\hline ALT $(\mathrm{U} / \mathrm{L})$ & $4.40 \pm 0.28$ & $19.80 \pm 1.21$ & $\mathrm{P} \leq 0.05$ & $\mathrm{~S}$ \\
\hline AST $(\mathrm{U} / \mathrm{L})$ & $3.70 \pm 0.20$ & $17.80 \pm 0.72$ & $\mathrm{P} \leq 0.05$ & $\mathrm{~S}$ \\
\hline Urea $(\mathrm{mmol} / \mathrm{L})$ & $3.30 \pm 1.02$ & $12.30 \pm 2.10$ & $\mathrm{P} \leq 0.05$ & $\mathrm{~S}$ \\
\hline Creatinine $(\mu \mathrm{mol} / \mathrm{L})$ & $66.52 \pm 3.30$ & $123.00 \pm 4.50$ & $\mathrm{P} \leq 0.05$ & $\mathrm{~S}$ \\
\hline
\end{tabular}

KEYS: Values are in means \pm Standard Deviation (SD); ALT = Alanine aminotransferase; AST = Aspartate aminotransferase; NS = Not statistically significant; $\mathrm{n}=$ number of rats 
In this study comparison was made between the mean values of plasma biochemical parameters such as alanine aminotransferase, aspartate aminotransferase, urea and creatinine in Rattus norvegicus domestica rats that were not administered with tetracycline or any other drug(s) (control group) with that of Rattus norvegicus domestica rats administered with $0.12 \mathrm{mg} / 0.2072 \mathrm{~kg}$ of tetracycline for two weeks (short term toxicity study) and four weeks (long term toxicity study) respectively as shown in Tables 1 and 2. The liver and kidney of these Rattus norvegicus domestica rats in the control group, short term toxicity study group and long term toxicity study group were also studied histomorhologically.

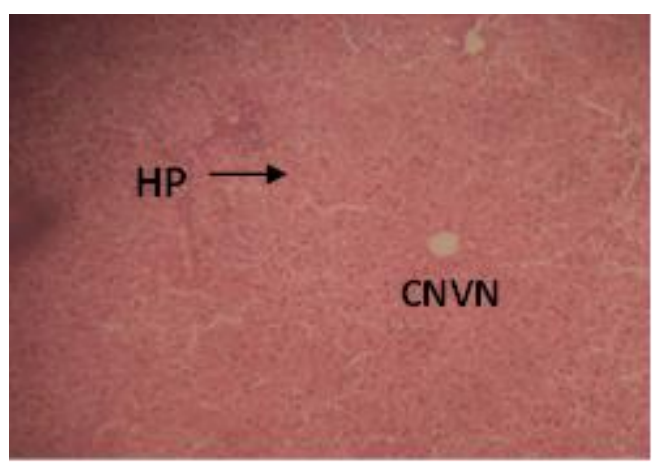

Figure 1 Photomicrograph of liver (short term toxicity study) slide showing normal hepatocyte (HP) and central vein (CNVN) as indicated by the arrows H\&E x100

The result in Table 1 showed that the mean values of plasma biochemical parameters: alanine aminotransferase and aspartate aminotransferase in the short term toxicity study were not statistically significant ( $p \geq 0.05)$ as compared with that of the control group which were not administered with any concentration of tetracycline. The biochemical finding which is established in this study is in conformity to the histomorphological study of the liver organ of the Rattus norvegicus domestica rats administered with the same $0.12 \mathrm{mg} / 0.2072 \mathrm{~kg}$ of tetracycline for two weeks (short term toxicity study) which revealed normal hepatocyte and central vein as shown in the photomicrograph slide of figure 1 compared with that of the Rattus norvegicus domestica rats that were not administered with any concentration of tetracycline control group) which also revealed normal hepatocyte and central vein as shown in the photomicrograph slide of figure 2 .

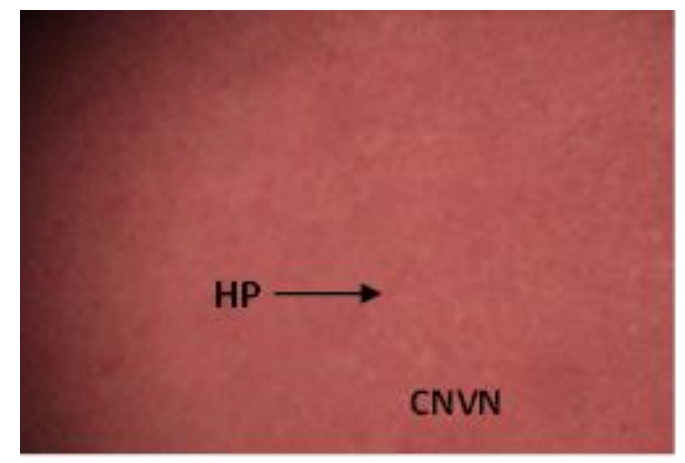

Figure 2 Photomicrograph of liver (control group) slide showing normal hepatocytes (HP) and central vein (CNVN) as indicated by the arrows H\&E x100.

Also in this table, the result showed that the mean values of plasma biochemical parameters: urea and creatinine in the short term toxicity study were not statistically significant $(\mathrm{p} \geq 0.05)$ as compared with that of the control group. The biochemical finding as established in this study is also in conformity to the histomorphological study of the kidney of the Rattus norvegicus domestica rats that were administered with the same $0.12 \mathrm{mg} / 0.2072 \mathrm{~kg}$ of tetracycline for two weeks (short term toxicity study) which revealed normal renal corpuscle with a clear Bowman's space and tubule as shown in the photomicrograph slide of figure 3 compared with that of the Rattus norvegicus domestica rats that were not administered with any concentration of tetracycline (control group) which also revealed normal renal corpuscle with clear Bowman"s space and tubule as shown in the photomicrograph slide of figure 4 . 


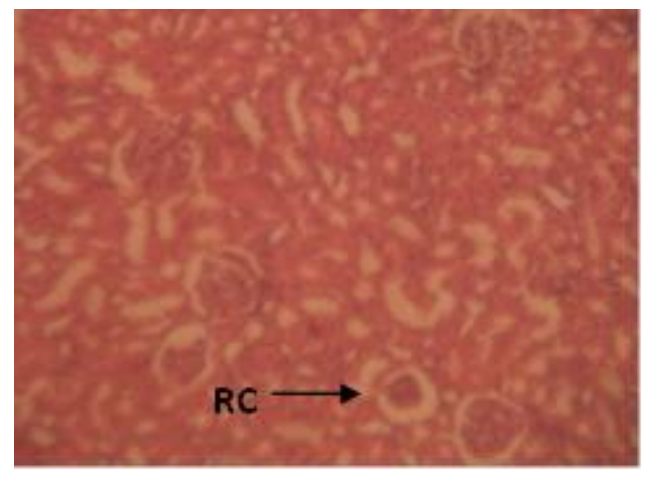

Figure 3 Photomicrograph of kidney (short term toxicity study) slide showing normal renal corpuscle (RC) with a clear Bowman's space as indicated by the arrow H\&E x100

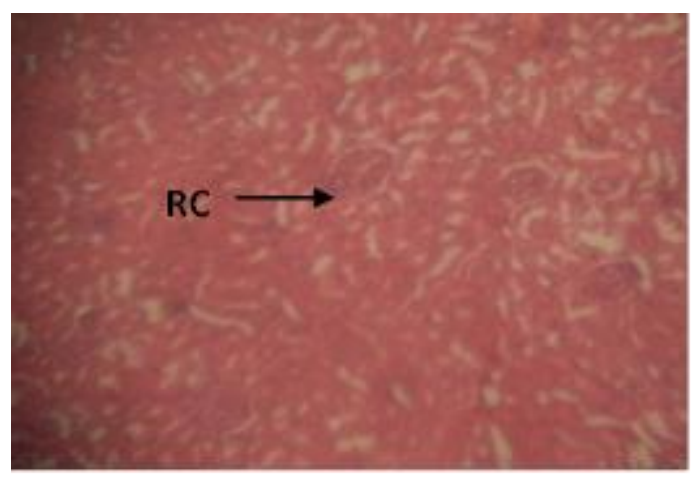

Figure 4 Photomicrograph of kidney (control group) slide showing normal renal corpuscle (RC) with a clear Bowman's space as indicated by the arrow H\&E x100

As shown further in this study, the results in Table 2 revealed that the mean values of plasma biochemical parameters: alanine aminotransferase and aspartate aminotransferase were significantly elevated ( $\mathrm{p} \leq 0.05)$ in the Rattus norvegicus domestica rats administered with $0.12 \mathrm{mg} / 0.2072 \mathrm{~kg}$ of tetracycline for four weeks (long term toxicity study) as compared with that of the control group which were not administered with any concentration of tetracycline. It is however presumed that these significant statistical elevations may be due to damage imposed on the liver of the Rattus norvegicus domestica rats as a result of the harmful effect induced by the long term administration of $0.12 \mathrm{mg} / 0.2072$ $\mathrm{kg}$ of tetracycline hydrochloride. This finding as confirmed in this present study and in agreement with the previous work of [9] is in conformity to the histomorphological study of the Rattus norvegicus domestica rats that were administered with $0.12 \mathrm{mg} / 0.2072 \mathrm{~kg}$ of tetracycline for four weeks (long term toxicity study) which revealed ballooned hepatocytes in the liver as shown in the photomicrograph slide of figure 5 compared with that of the Rattus norvegicus domestica rats that were not administered with any concentration of tetracycline (control group) which revealed normal hepatocyte as shown in the photomicrograph slide of figure 6.

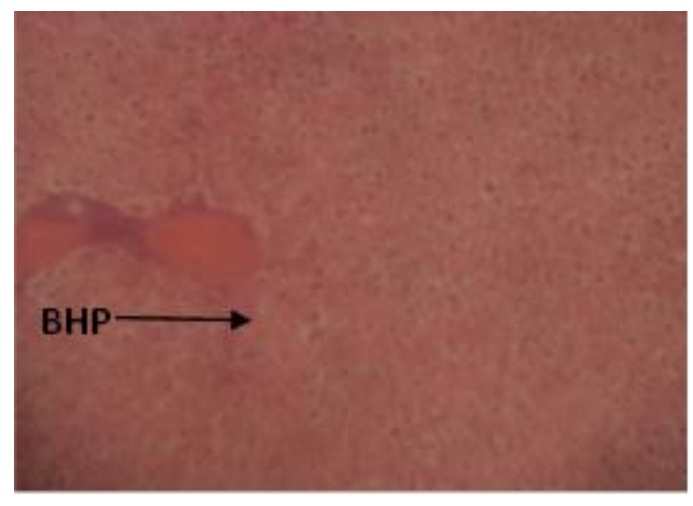

Figure 5 Photomicrograph of liver (long term toxicity study) slide showing ballooned hepatocytes (BHP) as indicated by the arrow. H\&E x100 


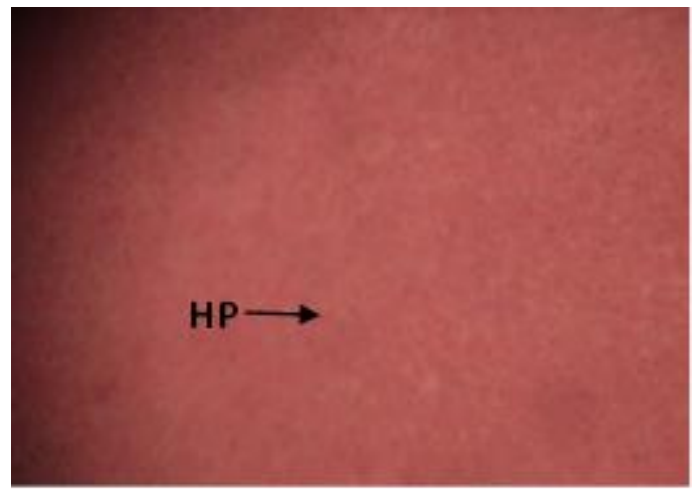

Figure 6 Photomicrograph of liver (control group) slide showing normal hepatocyte (HP) as indicated by the arrow. H\&E x100

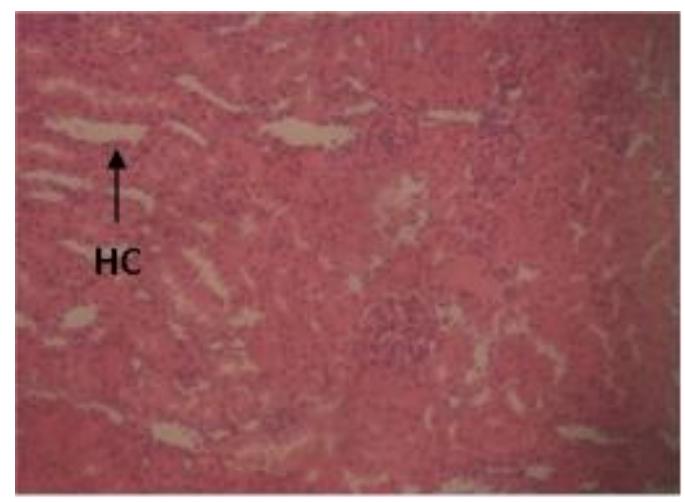

Figure 7 Photomicrograph of kidney (long term toxicity study) slide showing hyper cellularity (HC) as indicated by the arrow H\&E x100

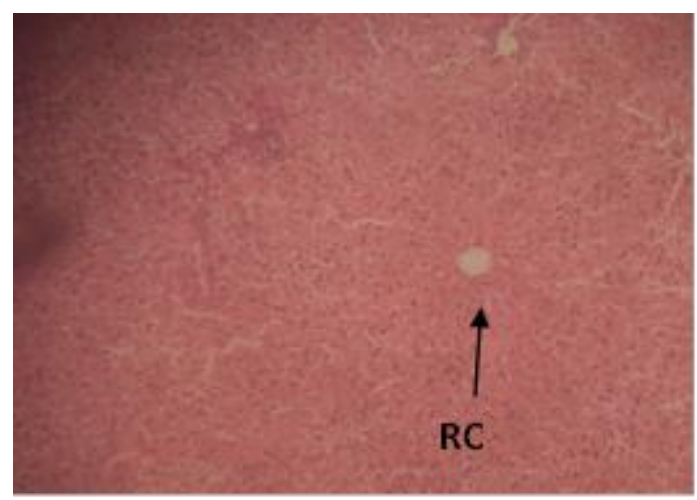

Figure 8 Photomicrograph of kidney (control group) slide showing normal renal corpuscle (RC) with a clear Bowman's space and tubules as indicated by the arrow H\&E x100

Also, in this Table, the results from this research work revealed that the mean values of plasma biochemical parameters: urea and creatinine were significantly higher statistically $(\mathrm{p} \leq 0.05)$ in the Rattus norvegicus domestica rats that were administered with $0.12 \mathrm{mg} / 0.2072 \mathrm{~kg}$ of tetracycline for four weeks (long term toxicity study) as compared with that of the control group which were not administered with any concentration of tetracycline. The significant increase in the mean values of plasma urea and creatinine which is in agreement with the previous work of [10] may be as a result of the degeneration and necrosis in the glomeruli and renal tubules due to the toxic action of tetracycline hydrochloride on the kidney, which is presumed to have prevented the filtration of the waste products (urea and creatinine) from the blood stream. This finding is in conformity to the histomorphological study of the kidney organ of the Rattus norvegicus domestica rats that were administered with the same $0.12 \mathrm{mg} / 0.2072 \mathrm{~kg}$ of tetracycline for four weeks (long term toxicity study) which revealed hypercellularity as shown in the photomicrograph slide of figure 7 compared with that 
of the Rattus norvegicus domestica rats that were not administered with any concentration of tetracycline (control group) which appeared normal as shown in the photomicrograph slide of figure 8.

\section{Conclusion}

In conclusion, this study has shown that the indiscriminate administration of $0.12 \mathrm{mg} / 0.2072 \mathrm{~kg}$ of tetracycline in Rattus norvegicus domestica rats for a period of four weeks (long term toxicity study) may induce liver and kidney disorders as revealed in the significant elevation of plasma hepato - renal biochemical parameters: alanine aminotransferase, aspartate aminotransferase, urea and creatinine as well as in the histomorphological study of these organs as shown in the photomicrograph slides while administration of the same $0.12 \mathrm{mg} / 0.2072 \mathrm{~kg}$ of tetracycline for two weeks (short term toxicity study) in Rattus norvegicus domestica rats has no adverse effects on the liver and kidney as revealed in the hepato - renal biochemical parameters: alanine aminotransferase, aspartate aminotransferase, urea and creatinine as well as in the histomorphological study of these organs as shown in the photomicrograph slides.

\subsection{Recommendations}

It is therefore recommended that:

- The public should be enlightened by the appropriate authorities on the need to avoid indiscriminate use of tetracycline.

- Long term administration of tetracycline without the prescription of a physician may nullify its benefits, thus indiscriminate use of the drug should be avoided.

- All patients on prolong administration of tetracycline with or without prescription of a physician are advised to go for liver and renal function tests in a Registered and Licensed Medical Laboratory facility.

\section{Compliance with ethical standards}

\section{Acknowledgments}

We acknowledge with thanks Mr. Samuel Anakwe Chukwuma for helping us anaesthetize and sacrifice the Rattus norvegicus domestica rats used for this study. Also, all the staff of Chemical Pathology unit of Niger Delta University, Wilberforce Island, Bayelsa State, Nigeria are well acknowledged for their maximum cooperation during the course of this studied

\section{Disclosure of conflict of interest}

We the authors of this article declare that we have no conflicting interest.

\section{Statement of ethical approval}

All the procedures carried out by the authors as regards this study were strictly in accordance with the ethical standards of National Guidelines for animal usage in research. Emmanuel Tonbra Egoro and Sonia Osaro Aibangbe participated fully in the analysis of all the biochemical parameters in plasma of the Rattus norvegicus domestica rats while Ikhide Godwin Ilegbedion was fully involved in the histomorphological examination of the liver and kidney organs excised from the Rattus norvegicus domestica rats.

\section{References}

[1] Bastos LFS, Merlo LA and Rocha Coecho MM. (2007). Characterization of the antinociceptive and antiinflammatory activities of doxycycline and minocycline in different experimental models. European Journal of Pharmacology, 576, 171-179.

[2] Chopra I and Roberts M. (2001). Tetracycline antibiotics mode of action, applications, molecular biology and epidemiology of bacteria resistance. Microbiology and Molecular Biology Reviews, 65(2), 232-260.

[3] Yin HQ, Kim M, Kim JH, Kong G, Lee MO, Kang KS, Yoon BI, Kim HL and Lee BH. (2006). Hepatic gene expression profiling and lipid homeostasis in mice exposed to steatogenic drug, tetracycline. Toxicological Sciences, 62(3), 222 -239. 
[4] Casarett and Doulls. (1986). Toxicology the basis science of poisons. Klaasen C.D, Amdur M.O., Doull, J., 3rd edition, Macmillan Publishing, 501-611.

[5] Uges DRA. (1996). Therapeutic and toxic drug concentrations. The TIAF Bulletin, 26, 1-34.

[6] Emmanuel T, Friday Okaka ANC, Ibiam Udu A and Sonni M. (2017).The toxicological effects of cement dust on hepatic and renal functions of cement factory workers. Int. J. Life Scs. Research, 5(3), 37-45.

[7] George GS, Wankasi MM and Egoro ET. (2014). Creatinine and urea levels as critical markers in end sytage renal failure. Research and Reviews: Journal of Medical and Health Sciences, 3(1), 41-44.

[8] Avwioro OG. (2014). Histochemistry and tissue pathology, principles and tecniques. 3rd edition, Claverianum Press Big Limited. ISBN 978-35627-9-7.

[9] Kikkawa R, Fujikawa M, Yamamoto T, Hamada Y, Yamada H and Horii I. (2006). In-vivo hepatotoxicity study of rats in comparism with in vitro hepatotoxicity screening system. Journal of Toxicology Sciences, 31, 23-24.

[10] Miller CS and McGarity GJ. (2009). Tetracycline-induced renal failure after dental treatment. Journal of the American Dental Association, 140(1), 56-60. 